\title{
Redesigning Educator Preparation Programs to Integrate Trauma-Informed Teaching Practices
}

\author{
Dr. Tammie T. Patterson \\ The University of Tennessee at Martin \\ 975 TN. Avenue \\ Parsons, TN 38363 United States \\ Dr. Karen S. DiBella \\ The University of Tennessee at Martin \\ 240 Gooch Hall \\ Martin, TN 38238 United States \\ Dr. Kimberly G. Williams \\ The University of Tennessee at Martin \\ 240 Gooch Hall \\ Martin, TN 38238 United States \\ Dr. Kimberly Gray \\ Kennesaw State University \\ 580 Parliament Way \\ Room BEB 367, MD 0122 \\ Kennesaw, GA 30144 United States \\ Mr. Texas Culver \\ The University of Tennessee at Martin \\ 315 South Washington St. \\ Ripley, TN 38063 United States
}

\begin{abstract}
:
Effectively preparing teachers to meet the needs of the vast majority of students who are coming to school with adverse childhood experiences is of critical importance to $21^{\text {st }}$ century learning. Trauma-informed practices are primarily about providing safe spaces and environments that foster and support children's social-emotional development so they are able to reach their potential. To be able to recognize when someone is experiencing adversity or not feeling safe, educators need to use appropriate listening skills, understand how to make connections, and provide support for other perspectives; seeing as best they can through the child's eyes. This paper will examine the need for educator preparation programs to provide trauma-informed practices that build social-emotional competencies and empower students who are affected by adversity to help them cope with the trauma.
\end{abstract}

Keywords -Trauma-Informed, Educator Preparation, Adverse Childhood Experiences (ACE)

\section{Introduction}

The Centers for Disease Control have deemed trauma as likely the most detrimental issue that America's children are facing today (CDC, 2019), yet few educator preparation programs include trauma-informed content into their curriculum.

Adverse Childhood Experiences, or ACEs, have been linked to a variety of early child development issues including the academic success of students in our nation's classrooms. Scientists tell us that a child's brain alters when they observe violence at home or in their communities, or experience poverty, eviction, and malnutrition (Tsavoussis, Stawicki, Stoicea, \& Papadimos, 2014). It adapts, altering its structure in a way that can be witnessed in brain scans. As a result, educators of these children will notice frequent "fight, flight, or freeze" responses to stress (Flannery, 2019). These responses are physiological responses to situations where a child feels a significant threat to their safety. While some students may "fight", which can include engaging or initiating a physical 
altercation with another student, others may choose "flight", where they run or disengage from the situation, while others simply "freeze", whereby they feel unable to respond; they are utterly "frozen" in the moment. All of these responses are often unable to be predicted and can certainly cause great angst for students and teachers and more importantly, can threaten the safety of everyone in the classroom.

\section{Significance}

A safe classroom should be an expectation for all students and teachers. In fact, for many students, school can provide be a safe haven away from a violent or stressful home. However, in an effort to create safer spaces that are more conducive to learning, it is important to understand how trauma and stress impact today's children. According to the National Traumatic Stress Network, one out of four children attending school has been exposed to a traumatic event that can affect learning and/ or behavior (NTST, 2008). With the current pandemic, it is of greater importance that educators be aware of the increasing needs of students impacted by trauma, as nearly all students have now experienced some level of trauma.

A single exposure to trauma can impair learning and yet chronic exposure to traumatic events can adversely affect attention, memory, and cognition (NTST, 2008). Teachers can see these affects nearly every day in today's classrooms. Trauma not only impairs learning, but also causes students physical and emotional distress, which can be displayed in many different ways in the classroom. Such behaviors can include isolation, fits of rage, outbursts, fighting, and much more. Since many of the behaviors can be unpredictable and impulsive, this can lead to a volatile situation, whereby teachers and students could ultimately be in danger. Unfortunately, many are illprepared to understand such behaviors and respond hastily, which further exasperates the trauma.

Therefore, it is of critical importance that teachers and more importantly, new teacher candidates, understand what trauma is, how it impacts learning, how to support students, and how to provide a safe classroom where all students can reach their full potential. To better understand trauma, educators should know what ACEsare through the ACE questionnaire (Table 1).

\section{Table 1: CYW Adverse Childhood Experiences Questionnaire (ACE-Q) Child}

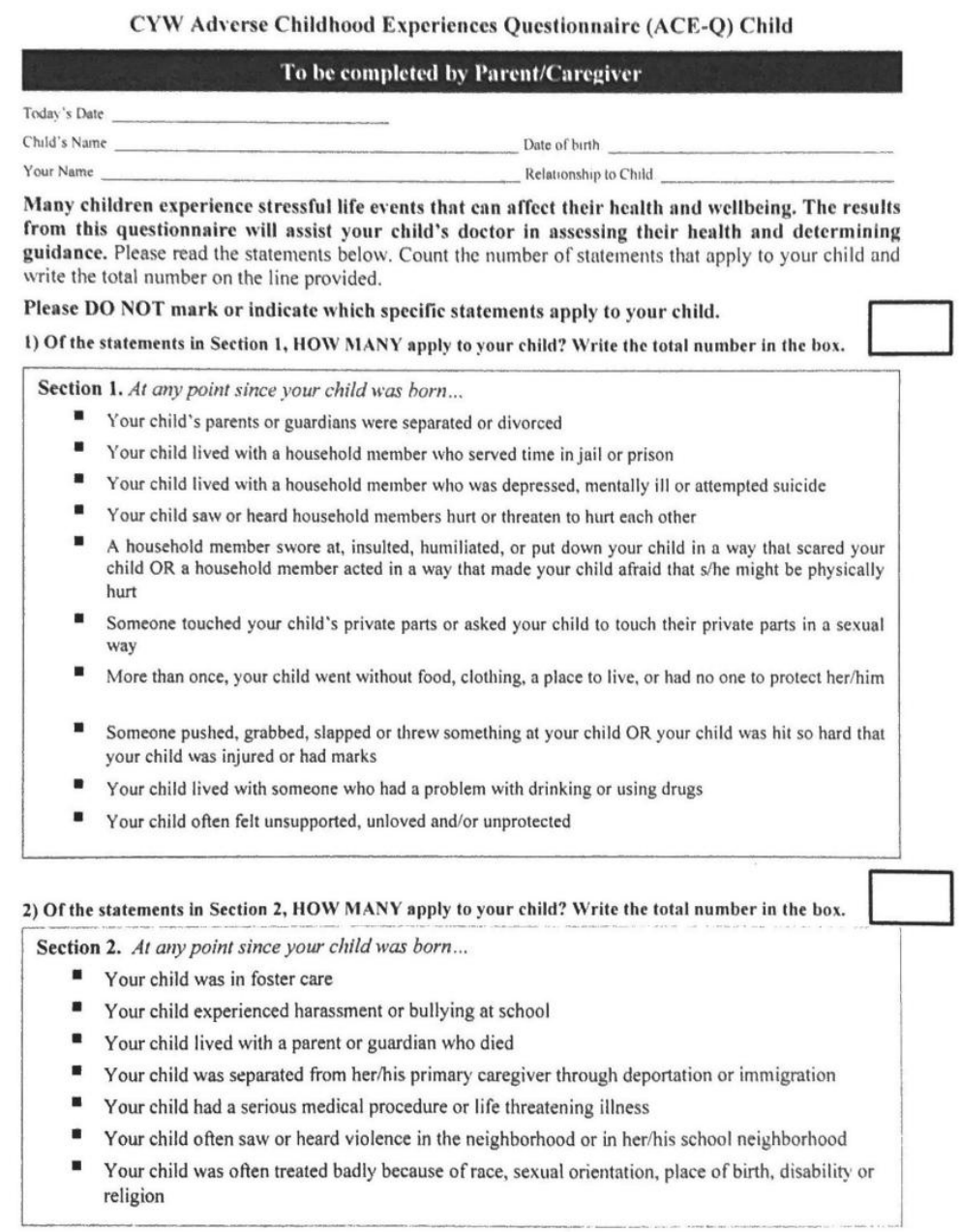


The term "ACEs" was initially used in 1998 following the publication of the Adverse Childhood Experiences (ACE Study), which was a groundbreaking study that found that not only were ACEs common among the general population, but also correlated to development and prevalence of health-related problems to youth as well (Center for Youth Wellness ACE-Questionnaire, 2015). Current research suggests that stress caused by ACEs can have a profound effect on children and actually alter their development.

Understanding the ACE questionnaire and how to create safe spaces and integrate inclusive instructional strategies will help foster classrooms that are more conducive to learning and assist educators in making appropriate datadriven decisions based on individual student needs. Conclusively, it is critical to recognize the need for change in educator preparation and current classroom practices to ensure the safety and thereby, success of all students in today's ever-changing world.

\section{Review of the Literature}

Up to two-thirds of U.S. children have experienced at least one type of serious trauma, such as abuse, neglect, natural disaster, or experiencing or witnessing violence. Trauma is possibly the largest public health issue facing our children today (CDC, 2019). Students who have faced trauma are especially prone to struggles with selfregulation, negative thinking, being on high alert, difficulty trusting adults, and inappropriate social interactions (Lacoe, 2013; Terrasi\& de Galarce, 2017). Traumatized children often are unable to express healthy emotions and instead demonstrate their distress through aggression, avoidance, over-response or under-response to sensory stimuli, or emotional numbing to threats in their environment, making them vulnerable to revictimization. These actions can feel aggressive to teachers who don't understand the underlying cause of the student's behavior, which can lead to misunderstandings, ineffective interventions, and missed learning time (Crosby, Howell, \& Thomas, 2018).

As empirical research grows that postulates that teachers, regardless of the school placement, should expect to have students in their classroom who are affected by multifaceted trauma, aspiring teachers must be trained on how to be impactful when teaching these students (Hobbs, Paulsen, \& Thomas, 2019). A significant number of students that teachers will serve in their classrooms have previously or will experience some type of trauma prior to the age of 18 that may change how they deal with their emotions, how they deal with friendships, and their ability to be academically successful in today's classroom (Van Der Kolk, 2014), yet teachers are largely underprepared for the difficulties that the students may face. Students impacted by trauma may experience many difficulties in the classroom, such as poor concentration, disorganization, aggressive behaviors, and a distrust of teachers, which can lead teachers to feel frustrated in the school setting (NCTSN, 2016; Ogata, 2017).In order to create a successful environment in the classroom and help to ensure success in the educational arenas each faculty member should be trained to facilitate strategies that can impact students who are traumatized, yet teachers, school psychologists, counselors, school social workers, and other faculty members receive little if any training during their undergraduate careers or continuing education (Ko, et al., 2008).

Students are incapable of learning if they do not feel protected, recognized, and cared for within their schools and by their teachers (Aupperle et al., 2012). When teachers are proactive and responsive to the needs of students suffering from traumatic stress and make small changes in the classroom that foster a feeling of safety, it makes a vast difference in their ability to learn.

Schools and classrooms should be a community that meets the needs of the students in all situations and the first step is being informed. Educating and supporting teachers regarding the growing needs of students impacted by trauma should be at the forefront of teacher preparation and school training. Teachers are the link between students academic and behavioral success; therefore, teachers must understand how to meet the needs of their students (Wiest-Stevenson \& Lee, 2016).

The critical goal of teacher preparation programs is to train trauma-informed teachers who are able to implement trauma-sensitive practices that will provide safe environments where students can feel valued and supported, are able to manage their emotions, decrease trauma-related symptoms that can impact behavior, and increase students ability to be in control of their learning and feel comfortable with what abilities they bring to the classroom (Dorado et al., 2016; Hummer, Crosland, \& Dollard,2009). Developing an educator preparation program that promotes trauma-informed practices requires a shift in the educational paradigm of classroom management. Although theorists have been promoting the idea of alternative approaches to disruptive and problematic behaviors for many years teacher preparation programs have not stressed the idea of positive student-teacher relationships (Chou et al., 2015; Mills \& McGregor, 2010; teRiele, 2014). Taking a trauma-informed approach to the training of aspiring teacher is necessary for the development of teacher who feels prepared to meet the needs of the student within today's school environment. 


\section{Call to Action}

Ensuring future educators are prepared to meet the diverse needs of twenty-first century learners requires reevaluation of current educator preparation programs (EPP) to effectively prepare teachers to work with students who have experienced trauma. Currently, trauma-informed teaching is not included in the accreditation process for EPPs and is not addressed as part of the conceptual framework for effectively preparing teacher candidates in most programs. Recognizing and understanding the potential impact of trauma is crucial in today's classrooms, primarily because of the impact on student behavior and their cognitive ability to respond appropriately to situations that may arise. According to the Robert Wood Johnson Foundation (2017), "over 38 percent of children in every state have had one of more Adverse Childhood Experiences." As a result of the current COVID-19 pandemic, one might assume that many more students have been exposed to at least one traumatic experience. Ensuring future teachers are prepared to recognize the signs of trauma and determine appropriate interventions is critical in today's classrooms. Traditional punitive disciplinary approaches are ineffective when working with these diverse populations; however, the majority of EPPs continue to focus on classroom management versus creating a trauma-informed environment that is safe and supportive.

The majority of EPPs have a required course sequence to prepare future teachers and include courses such as social work, educational psychology, methods courses, and a practicum experience. Intentional integration of traumainformed teaching practices should not only expose future educators to signs of trauma, but should also equip them with the necessary supports for student success. The Substance Abuse and Mental Health Services Administration (SAMHSA) (2014) has created a trauma-informed approach based on four Rs (Realize, Recognize, Respond, and Resist re-traumatization), which could provide the foundation for programmatic changes. According to SAMSHA (2014) "A program, organization, or system that is trauma-informed realizes the widespread impact of trauma and understands potential path for recovery; recognizes the signs and symptoms of trauma in clients, families, staff, and others involved with the system; and responds by fully integrating knowledge about trauma into policies, procedures, and practices, and seeks to actively resist re-traumatization" (p. 9).

Universities are encouraged to redesign their coursework to include a conceptual framework for creating traumainformed teaching practices, using the "four Rs" approach. This restructuring requires that University faculty assess exiting programs, determine course competencies and expectations, and intentionally create a program sequence that introduces, reinforces, and prepares teacher candidates for integrated practice of trauma-informed teaching practices (see Table 2).

Table 2: Implementation Plan for Trauma-Informed Teaching Redesign

Integration Phase 1: Introduce Phase 2: Reinforce

Four Rs Model Realize

Alignment

(SAMSHA, 2014)

Courses

Education Psychology

Introduction to Teaching

Equity and Diversity

Content

What is trauma?

ACE introduction and selfassessment

Statistical information
Assessment

Recognize

Methods

Classroom Management

Impact of trauma

Cognitive development issues associated with trauma

Case studies
Phase 3: Integrated Practice

Respond

Resist re-traumatization

Practicum (residency or student teaching)

Model trauma-informed best practices targeting environment, relationships, and selfregulation

A foundational understanding of trauma must begin early in the program and subsequent courses must apply this knowledge to understand the impact on practitioners and identify available resources. 


\section{Phase 1: Introduce}

Initially, teacher candidates will need to be provided a basic foundational understanding of trauma and its impact. Introductory courses would be those occurring in the beginning of the preparation program such as educational psychology, social work, introduction to teacher education, or diversity and equity. Emphasis would be placed on understanding trauma, current statistics, and an introduction to ACE. The trauma-informed model would align with Realize of the four Rs model and provide a basic understanding of how trauma can affect individuals, families, and other stakeholders (SAMSHA, 2014). Instruction would likely include having students self-assess to determine their ACE score and analyze the factors associated with trauma. Faculty must be prepared for potential reactions of individuals who may have experienced trauma and ensure anonymity.

Students should be presented with an overview of the material so they are aware of the sensitive and nature of the material being presented. Additional supports and resources may be needed for adverse reactions to the content (Honsinger and Brown, 2019).

\section{Phase 2: Reinforce}

The second phase of this model allows faculty to design activities focusing on the impact of trauma on all stakeholders. Teacher candidates should be expected to examine case studies as an impetus for learning; thus, aligning with Recognize of the four Rs model (SAMSHA, 2014). Specific classroom strategies targeting both behavior and cognitive development should be introduced and practical exercises would allow for a deeper understanding of trauma sensitivity.

\section{Phase 3: Integrated Practice}

Teacher candidates will experience the final two Rs (Respond and Resist Re-traumatization) in their culminating practicum by applying the principles of a trauma-informed classroom (SAMSHA, 2014). Specific emphasis must be placed on creating a safe classroom environment, building relationships with students, and teaching selfregulating strategies.

University Supervisors must also be prepared to provide feedback concerning appropriateness of interventions. This shift from traditional disciplinary measures may be new to many practitioners, requiring all parties to receive appropriate professional development.

\section{Conclusion}

EPPS can begin to prepare aspiring teachers to create a trauma-informed classroom; however, coursework must be intentionally designed to ensure teacher candidates are introduced to trauma sensitivity early in their program of study. Future educators must be able to observe signs of a student who has been traumatized, recognize the need for immediate intervention, and incorporate strategies to support students in the classroom. University programs must ensure adequate preparation using case studies and activities designed to foster an understanding of appropriate responses and behavior interventions for students who have experienced trauma. Faculty must also model effective strategies and ensure a safe learning environment that meets the needs of today's diverse twentyfirst century learners. Successful implementation depends on the willingness of faculty to collaborate, plan, and adapt instructional practices.

\section{References}

Aupperle, R. L., Melrose, A. J., Stein, M. B., \& Paulus, M. P. (2012). Executive function and PTSD: Disengaging from trauma. Neuropharmacology, 62(2), 686-694.

Bucci, M., Gutierrez Wang, L., Koita, K., Purewal, S., Silverio Marques, S., Burke Harris, N., Center for Youth Wellness ACE-Questionnaire User Guide, San Francisco, CA: Center for Youth Wellness, 2015.

CDC. (2019). Adverse childhood experiences. Retrieved from www.cdc.gov/violenceprevention/childabuseandneglect/acestudy/index.html

Chou, F., Kwee, J., Lees, R., Firth, K., Florence, J., Harms, J., . . Weaver, C. (2015). Nothing about us without us! Youth-led solutions to improve high school completion rates. Educational Action Research, 23(3), 436-459.

Crosby, S., Howell, P., \& Thomas, S. (2018). Social justice education through trauma-informed teaching. Middle School Journal, 49(4), 15-32.

Flannery, M. E. (2019, July 10). Inside a Trauma-Informed Classroom. Retrieved June 29, 2020, from http://neatoday.org/2019/07/10/inside-a-trauma-informed-classroom/

Heikonen, L., Pietarinen, J., Pyhältö, K., Toom, A., \&Soini, T. (2017). Early career teachers' sense of professional agency in the classroom: Associations with turnover intentions and perceived inadequacy in teacherstudent interaction. Asia-Pacific Journal of Teacher Education, 45(3), 250-266.

Lacoe, J. (2013). Too scared to learn? The academic consequences of feeling unsafe at school. Working Paper \#02-13. Institute for Education and Social Policy. 
Hobbs, C., Paulsen, D., \& Thomas, J. (2019). Trauma-Informed Practice for Pre-service Teachers. In Oxford Research Encyclopedia of Education.

Honsinger, C., \& Brown, M.H. (2019). Preparing trauma-sensitive teachers: Strategies for teacher educators. Teacher Educators' Journal, 12, 129-152.

Ko, S. J., Ford, J. D., Kassam-Adams, N., Berkowitz, S. J., Wilson, C., Wong, M., ... \& Layne, C. M. (2008). Creating trauma-informed systems: child welfare, education, first responders, health care, juvenile justice. Professional psychology: Research and practice, 39 (4), 396.

The National Child Traumatic Stress Network (2008). Child trauma toolkit for educators. Retrieved from www.NCTSN.org

The National Child Traumatic Stress Network (2016). Symptoms and behaviors associated with exposure to trauma. Retrieved from http://www.nctsn.org/trauma-types/early-childhoodtrauma/Symptoms-andBehaviors-Associated-with-Exposure-to-Trauma

Mills, M., \& McGregor, G. (2010). Re-engaging students in education: Success factors in alternative schools. Youth Affairs Network of Queensland (QUANQ).

Ogata, K. (2017). Maltreatment related trauma symptoms affect academic achievement through cognitive functioning: A preliminary examination in Japan. Journal of Intelligence, 5(32), 1-7

Robert Wood Johnson Foundation. (2017). Traumatic experiences widespread among U.S. Youth New Data Show. Retrieved from https://www.rwjf.org/en/ library/articles-and-news/2017/10/traumatic-experienceswidespread-among-u-s--youth--new-data-show.html

Substance Abuse and Mental Health Services Administration. (2014). SAMHSA's Concept of Trauma and Guidance for a Trauma-Informed Approach. HHS Publication No. (SMA) 14-4884. Rockville, MD: Substance Abuse and Mental Health Services Administration. Retrieved from https://store.samhsa.gov/product/SAMHSA-s-Concept-of-Trauma-and-Guidance-for-a-Trauma-InformedApproach/SMA 14-4884

teRiele, K. (2012). Learning Choices: A map for the future. Melbourne.

Tsavoussis, A., Stawicki, S., Stoicea, N., \&Papadimos, T. J. (2014). Child-witnessed domestic violence and its adverse effects on brain development: a call for societal self-examination and awareness. Frontiers in public health, 2, 178.

Wiest-Stevenson, C., \& Lee, C. (2016). Trauma-informed schools. Journal of evidence-informed social work, 13(5), 498-503. 